INNOVATIONS IN PRIMARY CARE

\title{
Connecting General Practitioners Through a Peer-Facilitated Community of Practice for Chronic Disease Care
}

\author{
Hyun Jung Song, BASc, MSc Jennifer Green, BSc, MSc \\ Mark Harris, MBBS, MD \\ Fan-Yin Li, BSc \\ Andrew Knight, MBBS, \\ MMedSci \\ Ann Fam Med 2020;18:179. https://doi.org/10.1370/afm.2490.
}

\section{THE INNOVATION}

General practitioners (GPs) are experts in their specialty but may lack opportunities to share their expertise and learn from each other. We trialed a peer-facilitated community of practice $(\mathrm{CoP}),{ }^{1}$ the first to provide peer learning and support to GPS around a locally relevant area of clinical interest-diabetes care-in the Fairfield area of New South Wales, Australia.

There has been much interest internationally in connecting GPs for learning. ${ }^{2-4}$ Communities of practice are characterized by their commitment to relationship-building through sustained interactions around a shared domain of interest. ${ }^{1}$ Despite demonstrated effectiveness across industries, ${ }_{1}^{5}$ they are not commonly utilized in Australian general practice.

\section{WHO \& WHERE}

Fairfield, an area of $102 \mathrm{~km}^{2}$, is one of the most culturally and linguistically diverse regions of Australia with significant socioeconomic disadvantage. There is a risk of professional isolation among the local GP workforce given its relatively high proportion of solo and foreign-trained practitioners. Identified opportunities for clinical education include chronic disease management, patient health literacy, and delivery of culturally competent care. ${ }^{6}$ Eight GPs from 7 practices, ranging in professional experience from 1 to 25 years, participated in the program. The group serves an ethnically diverse patient base with consultation languages including Arabic, Hindi, Croatian, and Serbian.

\section{HOW}

Program development was coordinated by a partnership of primary care academics (H.J.S., M.H., A.K.) and a regional pri-

Conflicts of interest: authors report none.

\section{CORRESPONDING AUTHOR}

Andrew Knight, MBBS, MMedSci

The Academic Primary and Integrated Care Unit

The Ingham Institute

1 Campbell St. Liverpool

NSW Australia 2170

awknight@aapt.net.au mary health workforce support team (F.Y.L., J.G.). Participants were recruited by a call for interest. Participation in the CoP was accredited as a continuing professional development activity.

Participants attended two 2-hour evening meetings in September 2018. Discussions were facilitated by a quality improvement specialist who is also a practicing Fairfield GP (A.K.). The first meeting involved ice-breakers, an introduction to CoPs, presentation of local diabetes outcome data, exploration of local issues in diabetes care, and teaching on quality improvement. Meeting 2 continued relationship building and introduced a local diabetes educator who provided information on the local specialist clinic. One participant volunteered to share deidentified diabetes-related data which was discussed. Participants shared their unique experiences of practicing in a very culturally diverse area and deliberated on the feasibility of an ongoing CoP.

GPs were interviewed and surveyed one month later to reflect on participation experience and future involvement.

\section{LEARNING}

Participants emphasized the novelty of the trial CoP, and the relevance of the content to clinical practice. The peer-facilitated CoP was valued as a rare opportunity to connect with regional colleagues in an "informal, GP-driven setting" that reduced a sense of isolation and informed cross-cultural consultations.

Participants cautioned that sustaining the CoP would depend on continued value through a focus on measured practice improvement and effective, efficient meetings. Most were positive about continuing participation. Lack of time was cited as a major barrier, but continuing professional development points may serve as a possible motivator. Continued collaboration with the regional primary health workforce support team is required to sustain the program beyond the trial project, to explore funding opportunities, and recruit peer facilitators. CoPs are being considered as part of a comprehensive regional quality improvement program for general practice.

Our experience shows that a structured CoP program can offer GPs a valuable peer-learning experience, with potential for creating lasting relationships between local colleagues. We recommend this innovation as a promising tool to support busy GPs within a regionally fragmented workforce.

For supplemental information, including author affiliations, key words, funding support, acknowledgments, and references, see http://www.AnnFamMed.org/content/18/2/179/suppl/DC1..

Submitted May 23, 2019; submitted, revised, June 26, 2019; accepted July 17, 2019. 